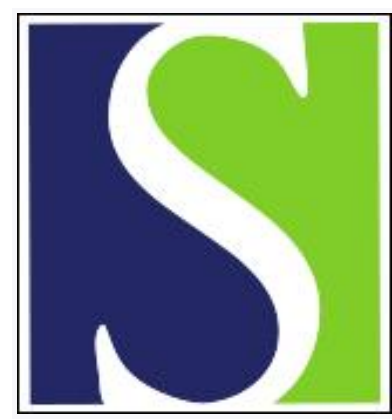

Scand J Work Environ Health 2007;33(3):204-215

https://doi.org/10.5271/sjweh.1129

Issue date: 30 Jun 2007

Randomized placebo-controlled field study of the effects of bright light and melatonin in adaptation to night work

by Bjorvatn B, Stangenes K, Øyane N, Forberg K, Lowden A, Holsten F, Åkerstedt T

Affiliation: Department of Public Health and Primary Health Care, University of Bergen, Kalfarveien 31, N-5018 Bergen, Norway. bjorn.bjorvatn@isf.uib.no

Refers to the following text of the Journal: 1998;24 suppl 3:69-75

The following articles refer to this text: 2008;34(4):297-306;

2010;36(6):515-516; 2014;40(6):543-556; 2021;47(2):145-153

Key terms: bright light; circadian rhythm; field study; melatonin; night work; objective ratings; placebo-controlled study; randomization; shift work; subjective ratings

This article in PubMed: www.ncbi.nlm.nih.gov/pubmed/17572830 


\title{
Randomized placebo-controlled field study of the effects of bright light and melatonin in adaptation to night work
}

\author{
by Bjørn Bjorvatn, MD,,${ }^{1,2}$ Kristine Stangenes, ${ }^{1}$ Nicolas Øyane, MD, ${ }^{1}$ Knut Forberg, ${ }^{1}$ Arne Lowden, PhD, ${ }^{3}$ \\ Fred Holsten, MD, 2, 4 Torbjørn Åkerstedt, PhD ${ }^{3}$
}

\begin{abstract}
Bjorvatn B, Stangenes K, Øyane N, Forberg K, Lowden A, Holsten F, Åkerstedt T. Randomized placebo-controlled field study of the effects of bright light and melatonin in adaptation to night work. Scand $J$ Work Environ Health 2007;33(3):204-214.
\end{abstract}

\begin{abstract}
Objectives This study evaluated the effects of bright light and melatonin on adaptation to night work on an oil rig in the North Sea.

Methods Seventeen persons working a schedule of 2 weeks on a 12-hour shift, with the first week on night shift and the second week on day shift (ie, the swing shift schedule) participated. In a randomized controlled crossover design, the shift workers received a placebo, melatonin ( $3 \mathrm{mg}$, 1 hour before bedtime), or bright light (30-minute exposure, individually scheduled) during the first 4 days on the night shift and during the first 4 days on the day shift. Subjective and objective measures of sleepiness (Karolinska Sleepiness Scale and a simple serial reaction-time test) and sleep (diary and actigraphy) were recorded.

Results Subjective measures indicated that melatonin modestly reduced sleepiness at work during the day shift and increased sleep by 15-20 minutes per day. Bright light gave values in between those of melatonin and the placebo, but with few significant results. According to the objective measures, bright light improved sleep to a minor degree during the night shift. Hardly any side-effects were reported.

Conclusions Melatonin and bright light modestly improved sleep and sleepiness in this field study. In well-controlled simulated nightwork studies, both melatonin and bright light are more effective in alleviating sleepiness and sleep problems. The less effect in this field study may be due to competing or conflicting factors present in real life or to an inoptimal timing and duration of the treatments.
\end{abstract}

Key terms circadian rhythm; objective ratings; shift work; subjective ratings.

Night work is associated with increased sleepiness and reduced performance while at work, and also sleeping problems after a night shift $(1,2)$, primarily because the circadian rhythm is not adapted for night work. Several studies indicate that the circadian rhythm of some workers may not adapt even after weeks of consecutive night work $(2,3)$. However, we have reported that offshore night workers seem to adapt to night work within a few days, at least when subjective measures are used (4). Lack of conflicting exposure to daylight in the morning was suggested as an explanation for the faster adaptation of these workers, when compared with that of onshore workers (4), the explanation being in agreement with the findings of Czeisler \& Dijk (5). Readaptation back to day life was, however, slow and troublesome for these offshore night workers (4).

Several countermeasures to the complaints of night workers have been suggested (ie, exposure to bright light, the intake of melatonin, the use of dark goggles when outside in daylight, napping at work, exercise, the intake of modafinil, etc) (2, 3, 6-13). Several carefully executed studies show that timed exposure to bright light will facilitate adaptation of the circadian rhythm $(3,6$, $12,14,15)$. Most of the studies have involved simulated night work, but also field studies have been encouraging, both offshore (16) and onshore (17-21). The effect of light depends on the timing of exposure relative to the nadir of the endogenous body temperature rhythm,

1 Department of Public Health and Primary Health Care, University of Bergen, Bergen, Norway.

2 Norwegian Competence Center for Sleep Disorders, Haukeland University Hospital, Bergen, Norway.

3 IPM - National Institute for Psychosocial Medicine, Karolinska Institute, Stockholm, Sweden.

4 Department of Psychiatry, University of Bergen, Bergen, Norway.

Reprint requests to: Dr B Bjorvatn, Department of Public Health and Primary Health Care, University of Bergen, Kalfarveien 31, N-5018 Bergen, Norway. [E-mail: bjorn.bjorvatn@isf.uib.no] 
which usually occurs $1-2$ hours before the habitual time of awakening (22). When bright light is given at the wrong circadian phase, adaptation to night work is impeded (23).

Melatonin has phase shifting properties (11, 24-27). Several studies have indicated that the drug may help adaptation to night work (27-32), but negative findings have also been reported $(12,33,34)$. To our knowledge, only two studies have compared the effects of bright light and melatonin, and, in both of these simulated nightwork studies, bright light was superior to melatonin $(12,35)$. Very few studies have investigated the effects of melatonin during actual night work (11), and none have done so in the particular context of off-shore settings.

The lack of real life studies on the effects of, particularly, melatonin, but also bright light, constitutes a problem for the application of laboratory-based knowledge to the real world. The latter presents several types of problems. The time for bright light treatment may conflict with worktasks. Environmental light may counteract bright light treatment. The ingestion of a drug to improve adjustment may not meet with widespread acceptance. However, for treatment with light or melatonin to be of any practical use to night workers, constraints of real life settings must be accepted. Our study is a first attempt to assess the effects of bright light and melatonin in a field study of shift workers in the offshore industry. Night workers complaining of problems related to shift work were followed with subjective and objective measures of sleep and sleepiness during the 14-day work period. The work schedule involved "swing shifts", that is, 1 week on a night shift followed by 1 week on a day shift. The workers were given melatonin and bright light in a randomized, double-blind, placebo-controlled crossover design.

\section{Study population and methods}

\section{Study population and design}

All persons ( $\mathrm{N}=109)$ working nights at an oil rig in the North Sea completed a questionnaire about possible sleep complaints in relation to shift work (data not shown). They were asked questions about the number of days they needed for adaptation to night work and readaptation back to day work and were asked to give an overall rating of their sleep problems in relation to shift work $(1=$ no problem, $2=$ some problems, $3=$ moderate problems, $4=$ severe problems, $5=$ very severe problems) (16). On the basis of an evaluation of the questionnaires, 38 workers were included in the study. The criteria for inclusion were problems adjusting to shift work, as indicated by a need for $>3$ days to adapt or readapt or an overall rating of their sleep problem as more than moderate $(>3)$.

Of the 38 included persons, 17 completed the study. The others did not participate or did not complete the study for the following reasons: (i) did not want to participate (8 persons), (ii) on sick leave (3 persons), (iii) stopped working this shift schedule (5 persons), (iv) quit or on leave (3 persons), or dropped out (2 persons, 1 claiming the study protocol took too much time and 1 wanting to take melatonin regularly during the work periods). The mean age of the 17 participants who completed the study was 42 (range 29-55) years. There was 1 woman and 16 men. They were in good health, as indicated by their biannual compulsory medical checkup. They enrolled in the study voluntarily and were not paid or otherwise compensated for their participation. Data were collected from April 2002 through April 2003. Light levels inside the oil rig were not recorded in this study. We had earlier measured light levels on a similar rig, where they varied from 20 to 700 lux, with an estimated average intensity in most areas of 200 to 300 lux (4).

The participants had a work schedule of 2 weeks on a 12-hour shift, with the first week on the night shift (1830 to 0630 ) and the second week on the day shift (0630 to 1830), a "swing shift" schedule. On the "swing" day, the workers ended their night shift at 0400 and started day work at 1000. After 3-4 weeks off work, this work schedule was repeated. There were small variations in the workhours between the participants and from day to day, due to unplanned overtime and individually adjusted work schedules.

The participants were evaluated on three consecutive work schedules of 14 days in a randomized crossover design using placebo capsules, melatonin capsules (3 mg), and bright light treatment. The placebo and melatonin capsules were identical in size and color, and the two treatments were administered blind, both for the participants and for everyone else involved in the study. The code was broken after all of the data had been collected and entered into worksheets so that any bias would be reduced. The participants were instructed to take the capsules 1 hour before bedtime, during the first 4 days during the first week and also during the first 4 days during the second week.

Similarly, bright light treatment was applied during the first 4 nights during the first week (night shift) and during the first 4 days during the second week (day shift). The exposure was scheduled individually by one of the authors (BB) on the assumption that the nadir of the circadian rhythm occurred about 2 hours before the participant's habitual time of awakening, and that the nadir occurred at a time when the participants usually had the most problems staying awake. Thus, in order to phase delay the endogenous circadian rhythm, 
we exposed the participants to bright light before the assumed time of the nadir, during both the first and second week of work. The assumed time of the nadir was determined from interviews with the participants, both before starting the night shift period and before the "swing" day. Between the participants, the start of bright light exposure ranged from midnight (0000) to 0500 during the night shift and from midday (1200) to 1430 during the day shift. Furthermore, the timing of the bright light exposure was delayed from day to day by about 1 hour to maximize the effects on the circadian rhythm. The participants were instructed to sit in front of a specially designed light box (ML-10000, MiljøLys AS, Åsgårdstrand Norway), $45 \times 15 \times 10$ centimeters in size, with a light intensity of 10000 lux at the recommended distance of 50 centimeters from eye level, for 30 minutes per day. They were told to avoid bright light after the scheduled bright light treatment, when light may phase advance the circadian rhythm.

Written informed consent was obtained from all of the participants. The study was approved by The Regional National Committee for Research Ethics, and the Norwegian Medicines Agency.

\section{Subjective measures}

Subjective ratings of sleepiness were obtained using the Karolinska Sleepiness Scale (KSS) (1) and a shortened version of the Accumulated Time with Sleepiness (ATS) scale (36). KSS is a 9-point verbally anchored scale with the following steps: $1=$ =ery alert, $3=$ alert, $5=$ neither alert nor sleepy, $7=$ =sleepy, but no problem staying awake, and $9=$ very sleepy, fighting sleep, effort to stay awake. The intermediate steps are not anchored verbally. The subjects rated sleepiness on the KSS every other hour while awake (at 2000, 2200, and so on). The ATS scale is designed to give an integrated rating representing sleepiness over longer periods [ie, accumulated sleepiness (as the percentage of time) during a 12-hour shift] (36). The participants were asked "Did you experience any of the following symptoms: heavy eyelids; feeling gravel-eyed; difficulties in focusing your eyes; irresistible sleepiness; reduced performance; and periods when you were fighting sleep?" The ATS ratings were recorded every day before going to bed during the 14-day work period. The participants also gave an overall rating of the day ( $1=$ very good, $3=$ good, $5=$ neither good nor bad, $7=$ bad, $9=$ very bad). In addition, they recorded their intake of coffee and tea on a daily basis. The intake of cola and tobacco was not recorded. Alcohol and sleep medication were not allowed during the study.

Subjective sleep was obtained with a modified version of the sleep diary presented by Morin (37). The diary consisted of the participant's estimates of the prior sleep episode and was recorded daily for the 14-day work period. The following measures were derived from the diary: bedtime, light out time, sleep onset latency, wake after sleep onset, number of awakenings, early morning awakening (ie, time spent in bed after final wake-up), final wake-up time, get-up time, total wake time (sleep onset latency + wake after sleep onset + early morning awakening), total sleep time, time in bed, sleep efficiency (ie, total sleep time as the percentage of time in bed), and an overall rating of the sleep episode ( $1=$ very restless, $5=$ very sound).

After the 2-week work period, the participants were asked in a simple questionnaire how many days they felt it took to adapt to night work and how many days they felt it took to readapt back to day work. They were also asked how they rated these 2 weeks of shift work as opposed to "regular" shiftwork periods $(1=$ much better than usual, $3=$ better than usual, $5=$ as usual, $7=$ worse than usual, 9=much worse than usual). In addition, they completed the Hospital Anxiety and Depression rating scale, since shift work and the treatments given the participants may have influenced mood. Last, they were asked to record any discomfort or side-effects of the treatments.

\section{Objective measures}

Objective ratings of sleepiness were obtained using a 5-minute simple serial reaction-time test on a Palm handheld computer (Palm Inc, Santa Clara, CA, USA). This was a modified version of similar tests developed by others (38-40). This 5-minute reaction time test has been validated and compared with longer tests (41). Fifty black squares were displayed on the screen at squarely distributed intervals (4.75-7.25 s) over 5 minutes. The participant's task was to respond to the stimuli by pressing a key to turn the square off. If no response was given within $1750 \mathrm{~ms}$, a new interval was started. Pressing the key before the square was displayed, or within $120 \mathrm{~ms}$, caused the response to be discarded and a warning to be displayed. The software that controlled the internal clock yielded data with a resolution of at least $0.5 \mathrm{~ms}$. Another part of the program calculated the mean reaction times. The reaction-time test was performed at three time points [0000 (midnight), 0300, 0600] during nights 1,3 , and 6 of the night shift (week 1) and similarly at three time points [(1200 (midday), 1500, 1800] during days 1,3 , and 6 of the day shift (week 2).

Objective sleep and wake activity was recorded with an Actiwatch recorder (Cambridge Neurotechnology Ltd, Cambridge, England), which is a small wrist-worn device, $1 \times 3 \times 3$ centimeters in size, containing an accelerometer that is optimized for highly effective sleep-wake inference from wrist activity. The Actiwatch recorder has been validated for documenting longitudinal changes in sleep patterns (42). The sensitivity of 
Table 1. Karolinska Sleepiness Scale (KSS) and reaction time-results from a three-way analysis of variance (ANOVA) for repeated measures. (Condition = placebo, melatonin, or bright light, day = day of the week, time = time point of the shift)

\begin{tabular}{|c|c|c|c|c|c|c|c|}
\hline & Condition & Day & Time & $\begin{array}{l}\text { Condition } \times \\
\text { day }\end{array}$ & $\begin{array}{l}\text { Condition } \times \\
\text { time }\end{array}$ & Day $\times$ time & $\begin{array}{l}\text { Condition } \times \\
\text { day } \times \text { time }\end{array}$ \\
\hline Sleepiness, KSS (N=17) & $F(2,32)$ & $F(5,80)$ & $F(5,80)$ & $F(10,160)$ & $F(10,160)$ & $F(25,400)$ & $F(50,800)$ \\
\hline $\begin{array}{l}\text { KSS, night shift }{ }^{\mathrm{a}} \\
\text { KSS, day shift }{ }^{\mathrm{a}}\end{array}$ & $\begin{array}{l}0.6 \\
2.8(P=0.087)\end{array}$ & $\begin{array}{r}30.9(P<0.001) \\
9.4(P<0.001)\end{array}$ & $\begin{array}{r}60.4(P<0.001) \\
5.1(P=0.024)\end{array}$ & $\begin{array}{l}1.7 \\
3.2(P=0.001)\end{array}$ & $\begin{array}{l}1.7 \\
0.5\end{array}$ & $\begin{array}{r}14.0(P<0.001) \\
2.9(P<0.001)\end{array}$ & $\begin{array}{l}0.8 \\
1.3\end{array}$ \\
\hline Mean reaction time & $F(2,26)$ & $F(2,26)$ & $F(2,26)$ & $F(4,52)$ & $F(4,52)$ & $F(4,52)$ & $F(8,104)$ \\
\hline $\begin{array}{l}\text { Reaction time, night } \\
\text { shift }(N=14)\end{array}$ & 1.3 & $15.4(P<0.001)$ & $8.8(P=0.001)$ & 0.6 & 0.1 & $3.1(P=0.026)$ & $2.1(P=0.073)$ \\
\hline Mean reaction time & $F(2,22)$ & $F(2,22)$ & $F(2,22)$ & $F(4,44)$ & $F(4,44)$ & $F(4,44)$ & $F(8,88)$ \\
\hline $\begin{array}{l}\text { Reaction time, day } \\
\text { shift }(N=12)\end{array}$ & 0.3 & 2.0 & 2.4 & $4.1(\mathrm{P}=0.025)$ & 0.8 & 0.3 & 0.5 \\
\hline
\end{tabular}

a Due to fewer time points, the swing day (0600 lacking from the nightshift and 0800 from day shift) was omitted in the three-way ANOVA.

the Actiwatch was set at medium. Data were collected in 1-minute epochs and transferred, via an interface, to a computer, and then analyzed (Actigraphy Sleep Analysis 2001, Cambridge Neurotechnology Ltd). The participants wore the actiwatch during the whole 2-week work period, except when taking a bath or shower. They were instructed to register the time they went to bed and the time they got out of bed by pressing a button on the actigraph. In case the participants had forgotten to do so, bedtime and rising time were obtained from the sleep diary. The following measures were derived from the actigraph: sleep onset latency, wake after sleep onset, early morning awakening (ie, time spent in bed after final wake-up), total wake time (sleep onset latency + wake after sleep onset + early morning awakening), total sleep time, time in bed, and sleep efficiency (total sleep time as the percentage of time in bed).

\section{Statistics}

The data were analyzed using SPSS version 11.5 (SPSS Inc, Chicago, IL, USA). The KSS and the reaction-time test were tested with a three-way analysis of variance (ANOVA) with condition (placebo, melatonin, bright light), day (day of the week), and time of day (KSS, six time points; reaction time, three time points) as factors. Most of the other variables (ATS scale, sleep diary, actigraphy) were tested with a two-way ANOVA using condition (placebo, melatonin, bright light) and day (day of the week) as factors. Separate ANOVA were performed for the night and day week. Posthoc comparisons were performed using LSD. The results of the Hospital Anxiety and Depression rating scale and data from the overall questionnaire were tested with paired t-tests. Pvalues were corrected for lack of compound symmetry using epsilon correction according to the Huyhn-Feldt procedure. The alpha level was set at 0.05 . Within-group effect sizes (pooled standard deviation) were calculated using the Cohen $d$ formula. In order to retain as many
Table 2. Sleepiness and sleep data-results of a two-way analysis of variance (ANOVA) for repeated measures. (Condition = placebo, melatonin, or bright light, day = day of the week)

\begin{tabular}{|c|c|c|c|}
\hline & Condition & Day & $\begin{array}{l}\text { Condition } \times \\
\text { day }\end{array}$ \\
\hline $\begin{array}{l}\text { Sleepiness ( } N=17) \text {, } \\
\text { night shift }\end{array}$ & $F(2,32)$ & $F(6,96)$ & $F(12,192)$ \\
\hline Heavy eyelids & 0.5 & $25.1(P<0.001)$ & 0.5 \\
\hline Irresistible sleepiness & 0.04 & $13.8(P<0.001)$ & 0.7 \\
\hline Fighting sleep & 0.6 & $13.5(\mathrm{P}<0.001)$ & 1.4 \\
\hline Quality of day & 0.02 & $15.6(P<0.001)$ & $2.0(P=0.056)$ \\
\hline $\begin{array}{l}\text { Sleepiness }(N=17) \text {, } \\
\text { day shift }\end{array}$ & $F(2,32)$ & $F(6,96)$ & $F(12,192)$ \\
\hline Heavy eyelids & 1.8 & $7.3(\mathrm{P}<0.001)$ & 1.3 \\
\hline Irresistible sleepiness & $3.2(P=0.056)$ & $5.1(\mathrm{P}=0.007)$ & $2.4(P=.050$ \\
\hline Fighting sleep & $3.7(\mathrm{P}=0.044)$ & $6.3(\mathrm{P}=0.001)$ & $3.0(P=0.010)$ \\
\hline Quality of day & 2.5 & $9.2(\mathrm{P}<0.001)$ & 0.9 \\
\hline $\begin{array}{l}\text { Sleep diary ( } N=16) \text {, } \\
\text { night shift }^{\mathrm{a}}\end{array}$ & $F(2,30)$ & $F(5,75)$ & $F(10,150)$ \\
\hline Sleep onset latency & $4.9(\mathrm{P}=0.020)$ & $2.9(P=0.058)$ & 1.2 \\
\hline Total sleep time & 2.3 & $2.1(P=0.090)$ & 0.9 \\
\hline Sleep efficiency & 0.2 & $6.3(P=0.001)$ & 1.5 \\
\hline $\begin{array}{l}\text { Sleep diary }(\mathrm{N}=16) \text {, } \\
\text { day shift }\end{array}$ & $F(2,30)$ & $F(6,90)$ & $F(12,180)$ \\
\hline Sleep onset latency & 0.04 & 1.3 & 1.0 \\
\hline Total sleep time & $4.2(\mathrm{P}=0.025)$ & $7.5(P<0.001)$ & 1.7 \\
\hline Sleep efficiency & $2.8(\mathrm{P}=0.078)$ & $6.5(\mathrm{P}<0.001)$ & 1.4 \\
\hline $\begin{array}{l}\text { Actigraphy ( } N=13) \text {, } \\
\text { night shift a }\end{array}$ & $F(2,24)$ & $F(5,60)$ & $F(10,120)$ \\
\hline Sleep onset latency & 2.4 & 1.1 & 0.8 \\
\hline Total sleep time & 2.2 & $2.6(P=0.044)$ & $1.9(P=0.084)$ \\
\hline Sleep efficiency & $2.8(\mathrm{P}=0.099)$ & 1.0 & 1.2 \\
\hline $\begin{array}{l}\text { Actigraphy }(\mathrm{N}=13) \text {, } \\
\text { day shift }\end{array}$ & $F(2,24)$ & $F(6,72)$ & $F(12,144)$ \\
\hline Sleep onset latency & $3.6(\mathrm{P}=0.072)$ & 0.3 & 0.9 \\
\hline Total sleep time & 1.4 & $7.6(P<0.001)$ & 1.3 \\
\hline Sleep efficiency & 0.8 & 0.7 & 1.3 \\
\hline
\end{tabular}

a The swing day was excluded in the analysis for the sleep diary and actigraphy data.

participants as possible in the analysis, we replaced missing data with careful estimates. If data from, for example, night 3 were missing, an average of night 2 and 4 was inserted. If night 7 or day 7 was missing, 
night or day 6 was inserted. If night 1 or day 1 was missing, night 2 or day 2 was inserted. The total number of missing data that were corrected varied between $1.1 \%$ and $3.6 \%$, except for the recorded intake of coffee and tea, for which $8.0 \%$ of the data were missing.

\section{Results}

Tables 1 and 2 (see page 4) summarize the results from the three-way and two-way ANOVA, respectively. The strongest effects of melatonin and bright light were observed in connection with day work for variables related to sleepiness. Otherwise, only modest effects of melatonin and bright light were found, whereas major differences were observed across days for almost all of the measured parameters. In addition, sleepiness and reaction times showed a significant variation across different time points of the shift (table 1).

\section{Subjective measures}

Sleepiness. In addition to using the KSS ratings at different time points during work, we averaged the ratings across the night shift and the day shift to obtain an overall measure of sleepiness. Figure 1 shows how the ratings changed significantly across days. After about four nights, sleepiness leveled off at values below 4, but there was a clear increase in sleepiness following the shift back to day work. Figure 1 also shows the KSS ratings at single time points during the night and day shift, showing that sleepiness clearly increased during the night. Table 3 shows the average sleepiness score during
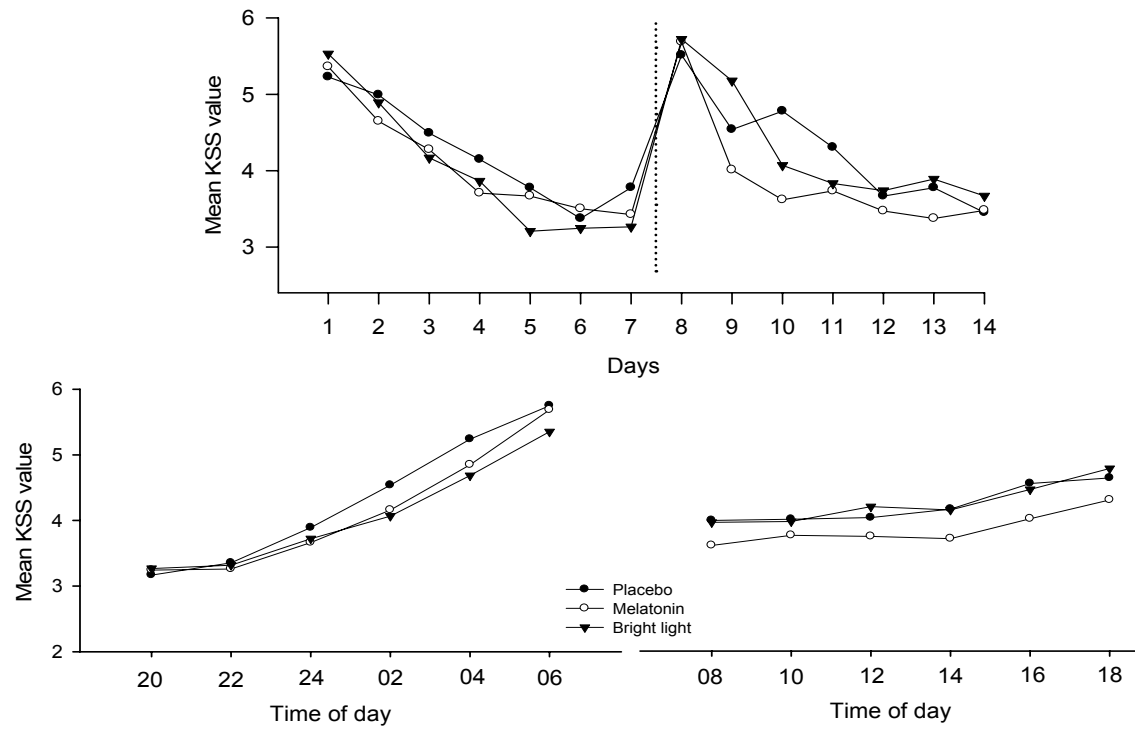

Figure 1. Mean ratings of sleepiness according to the Karolinska Sleepiness Scale (KSS). Top figure: the first 7 days represent KSS values during work at night, whereas the last 7 days represent KSS values during the day work that followed. Lower figures: the KSS values plotted at different times of the day for the night shift (left panel) and the day shift (right panel) (17 workers). Higher KSS values indicate more sleepiness. The standard deviations have been omitted for clarity.

Table 3. Subjective sleepiness and overall rating of the day, across each week ( $\mathrm{N}=17)$.

\begin{tabular}{|c|c|c|c|c|c|c|c|c|c|c|c|c|c|c|c|}
\hline \multirow[t]{2}{*}{ Shift } & \multicolumn{3}{|c|}{ Karolinska sleepiness scale a } & \multicolumn{3}{|c|}{ Heavy eyelids (\%) } & \multicolumn{3}{|c|}{ Irresistible sleepiness (\%) } & \multicolumn{3}{|c|}{ Fighting sleep (\%) } & \multicolumn{3}{|c|}{ Quality of day ${ }^{b}$} \\
\hline & Mean & SD & $\begin{array}{l}\text { Effect } \\
\text { size }^{c}\end{array}$ & Mean & SD & $\begin{array}{l}\text { Effect } \\
\text { size }^{c}\end{array}$ & Mean & SD & $\begin{array}{l}\text { Effect } \\
\text { size }^{c}\end{array}$ & Mean & SD & $\begin{array}{l}\text { Effect } \\
\text { size }^{c}\end{array}$ & Mean & SD & $\begin{array}{l}\text { Effect } \\
\text { size }^{c}\end{array}$ \\
\hline \multicolumn{16}{|l|}{ Night } \\
\hline Placebo & 4.3 & 1.0 & & 7.2 & 5.8 & & 2.2 & 2.6 & & 2.6 & 3.3 & & 3.4 & 0.9 & \\
\hline Melatonin & 4.1 & 1.1 & 0.19 & 8.2 & 7.1 & -0.15 & 2.3 & 2.4 & -0.04 & 2.1 & 2.3 & 0.18 & 3.4 & 1.1 & 0.00 \\
\hline Bright light & 4.0 & 0.8 & 0.33 & 7.0 & 5.5 & 0.04 & 2.1 & 2.4 & 0.04 & 1.8 & 1.6 & 0.31 & 3.3 & 0.8 & 0.12 \\
\hline \multicolumn{16}{|l|}{ Day } \\
\hline Placebo & 4.3 & 1.1 & & 11.2 & 11.2 & & 3.2 & 3.8 & & 3.4 & 3.5 & & 4.1 & 1.1 & \\
\hline Melatonin & 3.9 & $0.7^{d}$ & 0.43 & 6.3 & $7.5^{\mathrm{e}}$ & 0.51 & 1.6 & $2.5^{f}$ & 0.50 & 1.8 & $2.8^{g}$ & 0.50 & 3.4 & $0.6^{\mathrm{h}}$ & 0.79 \\
\hline Bright light & 4.3 & 1.0 & 0.00 & 10.1 & 13.4 & 0.09 & 3.0 & 3.8 & 0.05 & 2.8 & 2.8 & 0.19 & 3.8 & 1.0 & 0.29 \\
\hline
\end{tabular}

a Karolinska sleepiness scale: $1=$ very alert, $9=$ very sleepy, fighting sleep, effort to stay awake.

${ }^{b}$ Quality of day: $1=$ very good, $9=$ =ery bad.

${ }^{c}$ Compared with placebo effect.

d Significantly different from bright light ( $P=0.013)$, posthoc comparison.

e Nearly significantly different from the placebo $(P=0.053)$ and from bright light $(P=0.088)$, posthoc comparisons.

${ }^{\dagger}$ Significantly different from the placebo $(P=0.016)$ and nearly significantly different from bright light $(P=0.069)$, posthoc comparisons.

${ }^{g}$ Significantly different from the placebo $(P=0.021)$ and from bright light $(P=0.022)$, posthoc comparisons.

h Significantly different from the placebo $(P=0.041)$, posthoc comparison. 
the night and day week. Melatonin gave a significant reduction in sleepiness, when compared with the placebo and bright light. This reduction in sleepiness was present during the day shift, but not during the night shift. The ATS scale yielded results similar to those of the KSS (table 3). Melatonin gave significantly lower values for irresistible sleepiness and fighting sleep when compared with the placebo during the day shift (table 3). For most of the ratings, bright light generated sleepiness ratings in between those of the placebo and melatonin, although no significant differences from the placebo were observed. Melatonin improved the "quality of day", for ratings obtained during the day shift (figure 2, table 3).

The mean intake of coffee and tea ranged from 3.2 to 4.2 cups per day. No significant differences between the conditions were observed. It is noteworthy that, on the day shift, the intake was lowest after the intake of melatonin [3.7 versus 3.9 (placebo) and 4.0 (bright light) cups per day]. This finding suggests that the reduction in sleepiness after the intake of melatonin cannot be explained by an increase in coffee or tea.

Sleep diary. Melatonin gave significantly longer total sleep time than the placebo and bright light (figure 3, table 4). The difference averaged about 20 minutes per day. As demonstrated in figure 3, sleep was markedly reduced on the "swing" day ( $<4$ hours of sleep), but also the day after. In general, the participants slept longer during the nightwork period, when compared with during the daywork period (figure 3 , table 4 ). The bright light treatment gave a modest, but significant reduction in sleep onset latency, when compared with the placebo and melatonin, during the night shift. Sleep efficiency was significantly higher after the intake of melatonin

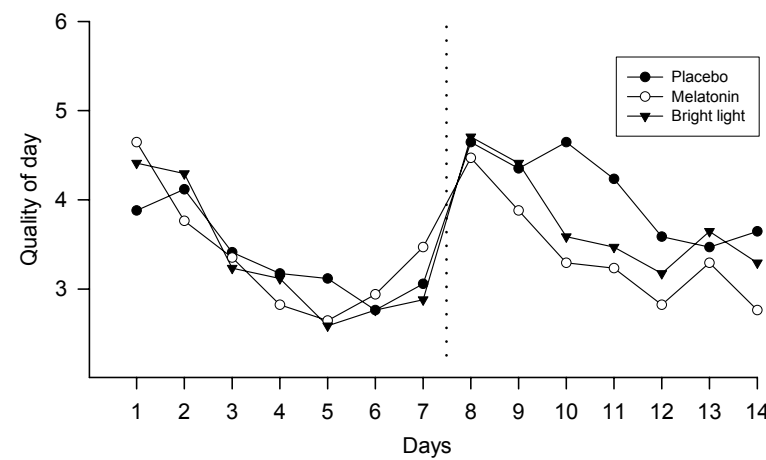

Figure 2. Mean overall rating of the day $(1=$ very good, $5=$ neither good nor bad, 9 = very bad). The first 7 days represent ratings during work at night, whereas the last 7 days represent ratings during the day work that followed (17 workers). The standard deviations have been omitted for clarity.

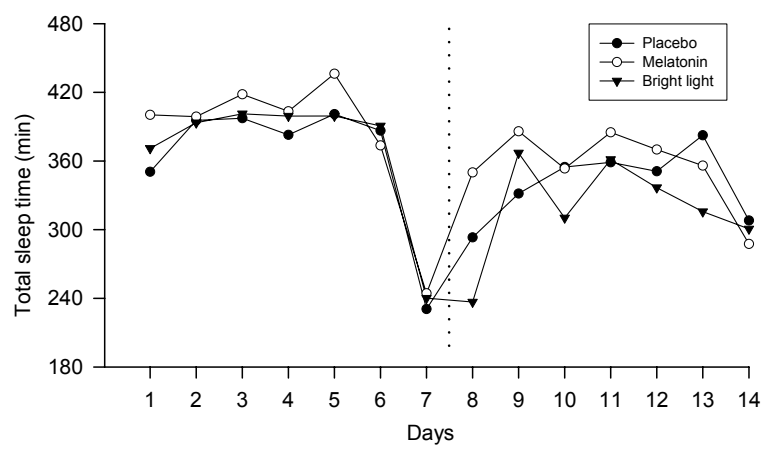

Figure 3. Mean subjective total sleep time according to the sleep diaries. The first 7 days represent subjective sleep lengths during work at night, whereas the last 7 days represent subjective sleep lengths during the day work that followed (16 workers). The standard deviations have been omitted for clarity.

Table 4. Data from the subjective sleep diary, across each week ( $\mathrm{N}=16$, one person was excluded because of poor compliance). The swing day has been excluded from the nightshift data.

\begin{tabular}{|c|c|c|c|c|c|c|c|c|c|c|c|c|}
\hline \multirow[t]{2}{*}{ Shift } & \multicolumn{3}{|c|}{ Sleep onset latency (minutes) } & \multicolumn{3}{|c|}{ Total sleep time (minutes) } & \multicolumn{3}{|c|}{ Sleep efficiency (\%) } & \multicolumn{3}{|c|}{ Sleep quality ${ }^{a}$} \\
\hline & Mean & $\mathrm{SD}$ & Effect size ${ }^{b}$ & Mean & SD & Effect size ${ }^{b}$ & Mean & $\mathrm{SD}$ & Effect size ${ }^{b}$ & Mean & SD & Effect size $^{b}$ \\
\hline \multicolumn{13}{|l|}{ Night } \\
\hline Placebo & 14 & 9 & . & 386 & 53 & . & 86 & 6 & . & 3.1 & 0.7 & . \\
\hline Melatonin & 13 & $8^{c}$ & 0.12 & 405 & $47^{d}$ & 0.38 & 87 & 7 & 0.15 & 3.1 & 0.8 & 0.00 \\
\hline Bright light & 9 & $5^{e}$ & 0.69 & 392 & 56 & 0.11 & 86 & 9 & 0.00 & 3.1 & 0.7 & 0.00 \\
\hline \multicolumn{13}{|l|}{ Day } \\
\hline Placebo & 19 & 16 & . & 340 & 38 & . & 83 & 8 & . & 2.7 & 0.7 & . \\
\hline Melatonin & 19 & 14 & 0.00 & 355 & $38^{\dagger}$ & 0.39 & 87 & $7^{g}$ & 0.53 & 2.8 & 0.8 & 0.13 \\
\hline Bright light & 17 & 17 & 0.12 & 318 & 35 & -0.60 & 80 & 9 & -0.35 & 2.8 & 0.7 & 0.14 \\
\hline
\end{tabular}

a Sleep quality: $1=$ very restless, $5=$ =very sound.

${ }^{\mathrm{b}}$ Compared with placebo effect.

c Significantly different from bright light $(P=0.023)$, posthoc comparison.

d Significantly different from the placebo $(P=0.047)$, posthoc comparison.

${ }^{\mathrm{e}}$ Significantly different from the placebo $(P=0.030)$, posthoc comparison.

${ }^{\dagger}$ Significantly different from bright light $(P=0.006)$, posthoc comparison.

${ }^{g}$ Significantly different from bright light $(P=0.014)$, posthoc comparison. 
when compared with after exposure to bright light, whereas there were no significant differences between the placebo and bright light. Sleep quality was rated as being similar in all three conditions.

Overall questionnaire and the Hospital Anxiety and Depression rating scale. Melatonin reduced the number of days it took to readapt to day work when compared with bright light, from 5.0 to 3.7 days (table 5). The placebo condition reached an intermediate level. There were no significant differences between the conditions regarding the number of days needed to adapt to night work or the rating of the 2 weeks of shift work when compared with "regular" shiftwork periods. The participants scored low on anxiety and depression, according to the Hospital Anxiety and Depression rating scale (table 5). There were no significant differences between the placebo, melatonin, and bright light conditions.

The participants reported very little discomfort or side-effects from the different treatments. Of a total of 51 registrations (17 participants, 3 conditions), discomfort and side-effects were recorded only four times, One participant reported headache following the placebo; one reported headache plus eye discomfort, one reported intensified dreaming following melatonin, and one reported headache after exposure to bright light.

\section{Objective measures}

Reaction time. There were no significant differences in the reaction times when the values were averaged across the night shift and day shift, respectively. Figure 4 shows the mean reaction times for each time point. There was a significant interaction between condition and day during the day shift (table 1). This finding was the result of increased reaction times after the intake of melatonin and the exposure to bright light during day 1 of the day shift (figure 4).

Sleep (actigraphy). Objective sleep recordings showed values similar to those of the sleep diary data, with

Table 5. Results of the overall questionnaire $(\mathrm{N}=16)$.

\begin{tabular}{|c|c|c|c|c|c|c|c|c|c|c|c|c|c|c|c|}
\hline \multirow[t]{3}{*}{ Condition } & \multirow{2}{*}{\multicolumn{3}{|c|}{$\begin{array}{l}\text { Days to adapt } \\
\text { to night work }\end{array}$}} & \multirow{2}{*}{\multicolumn{3}{|c|}{$\begin{array}{l}\text { Days to readapt } \\
\text { back to day work }\end{array}$}} & \multirow{2}{*}{\multicolumn{3}{|c|}{$\begin{array}{c}\text { Rating of } \\
\text { shiftwork period a }\end{array}$}} & \multicolumn{6}{|c|}{ Hospital Anxiety and Depression rating scale } \\
\hline & & & & & & & & & & \multicolumn{3}{|c|}{ Anxiety } & \multicolumn{3}{|c|}{ Depression } \\
\hline & Mean & SD & Effect size ${ }^{b}$ & Mean & SD & Effect size $^{b}$ & Mean & SD & Effect size ${ }^{b}$ & Mean & SD & Effect size $^{b}$ & Mean & SD & Effect size ${ }^{b}$ \\
\hline Placebo & 2.7 & 1.0 & & 4.4 & 1.5 & & 5.6 & 1.8 & & 3.4 & 2.5 & & 2.9 & 2.6 & \\
\hline Melatonin & 2.7 & 0.9 & 0.00 & 3.7 & $1.1^{\mathrm{c}}$ & 0.53 & 4.8 & 1.3 & 0.51 & 3.8 & 2.5 & -0.16 & 3.1 & 2.7 & -0.08 \\
\hline Bright light & 2.5 & 0.9 & 0.21 & 5.0 & 1.5 & -0.40 & 5.5 & 1.9 & 0.05 & 3.8 & 2.8 & -0.15 & 3.5 & 2.3 & -0.24 \\
\hline
\end{tabular}

a Rating of shiftwork period: $1=$ much better than usual, $5=$ as usual, $9=$ much worse than usual.

${ }^{\mathrm{b}}$ Compared with the placebo.

c Significantly different from bright light $(P=0.024)$.

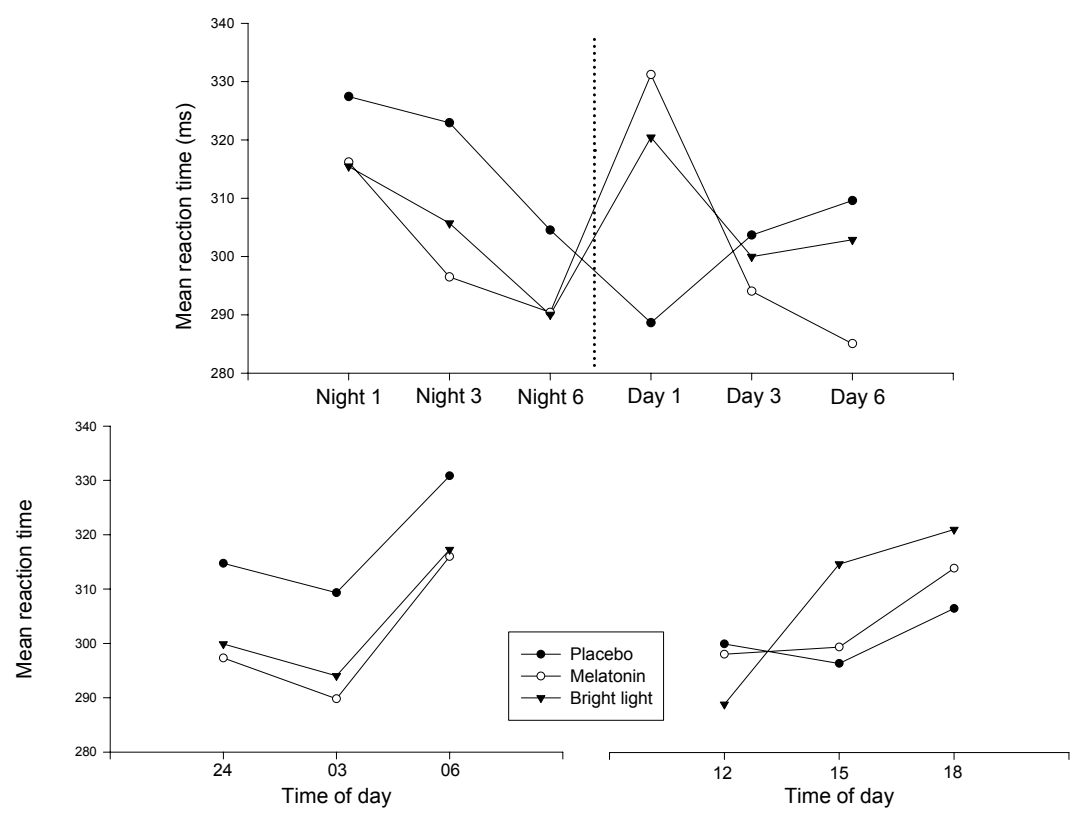

Figure 4. Mean reaction times in milliseconds. The reaction times were measured objectively at three points [0000 (midnight), 0300, and 0600] during nights 1, 3, and 6 of the night shift (14 workers) and similarly at three points [1200 (midday), 1500, and 1800] during days 1,3 , and 6 of the day shift (12 workers). Top figure: averaged day values. Lower figures: averaged time of the day values. The standard deviations have been omitted for clarity. 
longer total sleep time during the nightwork period, when compared with the daywork period, and markedly reduced sleep on the "swing" day (figure 5, table 6). Surprisingly, the statistical analysis showed that melatonin increased the sleep onset latency when compared with the effect of bright light $(\mathrm{P}=0.04)$ and the placebo (at the trend level) during the day shift. Furthermore, bright light modestly increased total sleep time when compared with the placebo (at trend level) during night shift. Thus objective recordings indicated that bright light gave the best sleep, although no major differences were found between the conditions.

\section{Discussion}

This is the first study comparing the effects of bright light and melatonin with respect to subjective and objective measures of sleepiness and sleep in relation to night work among real shift workers. The design was a randomized placebo-controlled crossover study. In general, the effects were modest, especially for the nightwork period. According to the subjective measures, melatonin reduced sleepiness at work during the dayshift week and increased sleep by 15-20 minutes per day. According to most of the subjective measures, bright light gave values in between those of melatonin and the placebo. The objective measures indicated that the reaction times did not differ between the conditions, whereas bright light improved sleep to a minor degree. Due to the multiple statistical tests, one may argue that the data indicate that bright light and melatonin were relatively ineffective for adaptation to night work in this real life setting. However, it should be emphasized that, although the effects were relatively small, the placebo condition

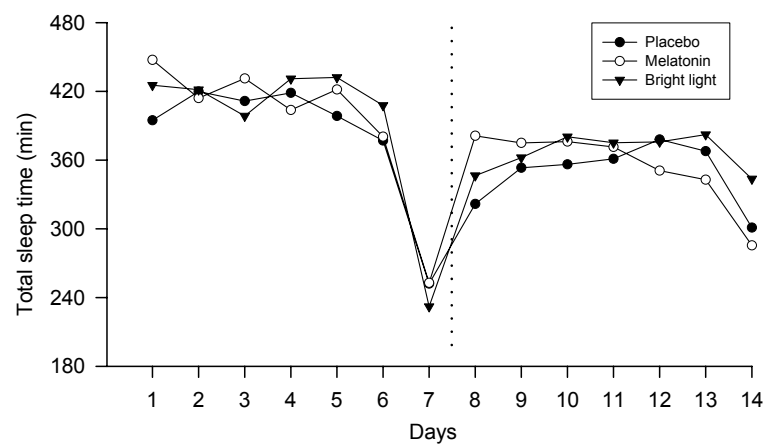

Figure 5. Mean objective total sleep time according to the actigraphy. The first 7 days represent objective sleep lengths during the nights, whereas the last 7 days represent objective lengths during the day work that followed ( 15 workers). The standard deviations have been omitted for clarity.

gave higher sleepiness and less sleep for nearly all of the measured variables.

Several studies have indicated that both bright light and melatonin are effective in alleviating sleepiness and sleep problems in shift work $(3,8,14,16-21,27,28$, $30-32,35)$. Nearly all of the studies have been carried out under well-controlled simulated nightwork conditions. [See the paper by Burgess et al for a review (11).] In real night work, many factors possibly influencing adaptation are difficult to control, like daylight exposure, coffee intake, exercise, and the like. Furthermore, when real night workers are studied, a major issue is to avoid making changes other than those needed for the intervention. The purpose of our study was to carry out an effectiveness study, not an efficacy study (43), as in simulated night work. Thus, even though strategies for circadian adaptation may work under simulated conditions, a lack of effect or less effect is commonly found when the strategy is introduced into a real life setting. This situation does not mean that the strategy is

Table 6. Objective sleep data, from the actigraphy, across each week ( $N=15$, two participants were excluded due to technical problems with the actiwatches).

\begin{tabular}{|c|c|c|c|c|c|c|c|c|c|}
\hline \multirow[t]{2}{*}{ Shift } & \multicolumn{3}{|c|}{ Sleep onset latency (minutes) } & \multicolumn{3}{|c|}{ Total sleep time (minutes) } & \multicolumn{3}{|c|}{ Sleep efficiency (\%) } \\
\hline & Mean & SD & Effect size $^{a}$ & Mean & SD & Effect size ${ }^{a}$ & Mean & SD & Effect size ${ }^{a}$ \\
\hline \multicolumn{10}{|l|}{ Night } \\
\hline Placebo $^{b}$ & 6 & 6 & & 403 & 60 & & 86 & 9 & \\
\hline Melatonin ${ }^{\mathrm{b}}$ & 9 & 12 & -0.32 & 416 & 48 & 0.24 & 87 & $8^{c}$ & 0.12 \\
\hline Bright light ${ }^{b}$ & 6 & 8 & 0.00 & 419 & $63^{d}$ & 0.26 & 88 & 8 & 0.23 \\
\hline \multicolumn{10}{|l|}{ Day } \\
\hline Placebo & 6 & 6 & & 348 & 48 & & 85 & 11 & \\
\hline Melatonin & 15 & $18^{e}$ & -0.67 & 355 & 46 & 0.15 & 86 & 10 & 0.10 \\
\hline Bright light & 7 & 9 & -0.13 & 367 & 62 & 0.34 & 87 & 9 & 0.20 \\
\hline
\end{tabular}

a Compared with the placebo effect.

b Swing day excluded.

${ }^{c}$ Nearly significantly different from bright light $(P=0.086)$, posthoc comparison.

${ }^{a}$ Nearly significantly different from the placebo $(P=0.082)$, posthoc comparison.

e Significantly different from bright light $(P=0.042)$ and nearly significantly different from the placebo $(P=0.086)$, posthoc comparisons. 
ineffective, but competing or conflicting factors influence sleepiness and sleep in real life settings. The modest effects found in our study should, however, not be an obstacle to further attempts to implement and evaluate bright light and melatonin in shiftwork settings.

Our study has several limitations. The effects of bright light are dependent on the time of the exposure. Bright light exposure before the nadir of the circadian body temperature rhythm causes a phase delay, whereas exposure after the nadir advances the circadian rhythm $(11,22)$. Thus incorrectly timed bright light impedes adaptation to night work (23). In our study, we had no objective measures for circadian phase. Bright light was scheduled individually on the basis of a clinical interview with the worker. The timing of bright light was based on the assumption that the nadir is located 1-2 hours before the habitual time of awakening (22). The timing of the bright light exposure was especially complicated after the 7 days of consecutive night work, when the workers shifted back to day work. Correctly estimating the nadir on the basis of a clinical interview in such a situation is difficult. Using a similar shift schedule (swing shift), Gibbs et al (44) showed that oil rig workers adapted to a night shift during the first week, whereas there were large individual variations during the day shift when a urinary melatonin metabolite was used as the circadian marker. They concluded that the participants adapted to the night shift, but not back to the day shift. This study had, unfortunately, not yet been published when our study commenced. In retrospect, we believe that the timing of bright light was not appropriate for some of the workers, and a better strategy would have been to advance rather than delay the phase of the rhythms. In other words, we believe that, for some of the workers, the circadian rhythm phase had not been delayed during the first week to the extent that we had assumed.

Another important aspect about bright light treatment is the duration of exposure. In our study, we used 30 minutes of exposure, but with a high intensity (10 000 lux). Most other studies have used longer exposure times [see the paper by Burgess et al for a review (11)], and this shorter exposure time may explain the smaller effect attained in our study. However, we used 30-minute exposure in our previous study on offshore workers and found subjective improvements (16), and, for winter depression and sleep phase disorders, 30-minute exposure to 10000 lux has been used with success (45). Longer exposure times would likely have improved the results of our study, but would have also complicated the implementation in actual life settings. Environmental light affects circadian rhythm (46), and this effect may have counteracted the effects of the bright light. However, the oil rig is a self-contained living and working space in which most work is carried out indoors, with minimal daylight interference. In addition, our study was a randomized-controlled crossover study, indicating that all three conditions (placebo, melatonin, bright light) were given throughout the year. Thus, seasonal variation in lighting conditions was unlikely to have played a major role.

The effects of melatonin are dependent on the dose and time of administration $(25,27,31)$. In our study, we administered melatonin ( $3 \mathrm{mg}$ ) 1 hour before bedtime, without any consideration of circadian phase. This choice was made for simplicity. We believe that a better timing of melatonin may have improved the results, both with respect to subjective and objective measures. Melatonin also has acute soporific effects (47), possibly influencing some of the results. However, during the day shift, melatonin increased actigraphically measured sleep onset latency, suggesting a lack of soporific effects.

In an effectiveness study, one major issue is whether the intervention should be recommended or not. The present data imply that bright light, and especially melatonin, may help to alleviate sleepiness and improve sleep (at least subjective sleep) among night workers, but, in our study, the effects were modest. Thus our study implies that these countermeasures should not uncritically be introduced in real nightwork settings. From a clinical standpoint, we believe that some workers benefit, whereas others may not. Thus careful individual evaluation of night workers, before and after an intervention trial, is therefore recommended. The question is whether an actual work situation permits extensive individual evaluation. A procedure for establishing the circadian phase through, for example, dim-light melatonin onset may be too cumbersome for practical use. Still, this is an important area of future research if melatonin or bright light are to be routine aids to shift workers.

In addition to the data on the treatment effects, our study also provides data on adaptation and readaptation to night work, on a daily basis. These data have been discussed in detail elsewhere (48).

In conclusion, this randomized placebo-controlled crossover field study on an oil rig in the North Sea showed that melatonin and bright light had modest effects on sleepiness and sleep. The timing and duration of bright light and melatonin were not optimal, possibly explaining the smaller effect than what has been found in simulated shiftwork situations.

\section{References}

1. Åkerstedt T. Psychological and psychophysiological effects of shift work. Scand J Work Environ Health. 1990;16 suppl 1:67-73.

2. Eastman CI, Boulos Z, Terman M, Campbell SS, Dijk DJ, 
Lewy AJ. Light treatment for sleep disorders: consensus report, VI: shift work. J Biol Rhythms. 1995;10(2):157-64.

3. Czeisler CA, Johnson MP, Duffy JF, Brown EN, Ronda JM, Kronauer RE. Exposure to bright light and darkness to treat physiologic maladaptation to night work. N Engl J Med. 1990;322(18):1253-9.

4. Bjorvatn B, Kecklund G, Åkerstedt T. Rapid adaptation to night work at an oil platform, but slow readaptation after returning home. J Occup Environ Med. 1998;40(7):601-8.

5. Czeisler CA, Dijk DJ. Use of bright light to treat maladaptation to night shift work and circadian rhythm sleep disorders. J Sleep Res. 1995;4(S2):70-3.

6. Baehr EK, Fogg LF, Eastman CI. Intermittent bright light and exercise to entrain human circadian rhythms to night work. Am J Physiol. 1999;277(6 Pt 2):R1598-604.

7. Eastman CI. High-intensity light for circadian adaptation to a 12-h shift of the sleep schedule. Am J Physiol. 1992;263(2 Pt 2):R428-36.

8. Eastman CI, Stewart KT, Mahoney MP, Liu L, Fogg LF. Dark goggles and bright light improve circadian rhythm adaptation to night-shift work. Sleep. 1994;17(6):535-43.

9. Monk TH. What can the chronobiologist do to help the shift worker? J Biol Rhythms. 2000;15(2):86-94.

10. Åkerstedt T. Shift work and disturbed sleep/wakefulness. Sleep Med Rev. 1998;2(2):117-28.

11. Burgess HJ, Sharkey KM, Eastman CI. Bright light, dark and melatonin can promote circadian adaptation in night shift workers. Sleep Med Rev. 2002;6(5):407-20.

12. Crowley SJ, Lee C, Tseng CY, Fogg LF, Eastman CI. Combinations of bright light, scheduled dark, sunglasses, and melatonin to facilitate circadian entrainment to night shift work. J Biol Rhythms. 2003;18(6):513-23.

13. Czeisler CA, Walsh JK, Roth T, Hughes RJ, Wright KP, Kingsbury L, et al. Modafinil for excessive sleepiness associated with shift-work sleep disorder. N Engl J Med. 2005;353(5):476-86.

14. Horowitz TS, Cade BE, Wolfe JM, Czeisler CA. Efficacy of bright light and sleep/darkness scheduling in alleviating circadian maladaptation to night work. Am J Physiol Endocrinol Metab. 2001;281(2):E384-91.

15. Martin SK, Eastman CI. Medium-intensity light produces circadian rhythm adaptation to simulated night-shift work. Sleep. 1998;21(2):154-65.

16. Bjorvatn B, Kecklund G, Åkerstedt T. Bright light treatment used for adaptation to night work and re-adaptation back to day life: a field study at an oil platform in the North Sea. J Sleep Res. 1999;8(2):105-12.

17. Boivin DB, James FO. Circadian adaptation to night-shift work by judicious light and darkness exposure. J Biol Rhythms. 2002;17(6):556-67.

18. James FO, Walker CD, Boivin DB. Controlled exposure to light and darkness realigns the salivary cortisol rhythm in night shift workers. Chronobiol Int. 2004;21(6):961-72.

19. Lowden A, Åkerstedt T, Wibom R. Suppression of sleepiness and melatonin by bright light exposure during breaks in night work. J Sleep Res. 2004;13(1):37-43.

20. Eastman CI, Martin SK. How to use light and dark to produce circadian adaptation to night shift work. Ann Med. 1999;31(2):87-98.

21. Stewart KT, Hayes BC, Eastman CI. Light treatment for NASA shiftworkers. Chronobiol Int. 1995;12(2):141-51.

22. Dijk DJ, Boulos Z, Eastman CI, Lewy AJ, Campbell SS, Terman M. Light treatment for sleep disorders: consensus report, II: basic properties of circadian physiology and sleep regula- tion. J Biol Rhythms. 1995;10(2):113-25.

23. Mitchell PJ, Hoese EK, Liu L, Fogg LF, Eastman CI. Conflicting bright light exposure during night shifts impedes circadian adaptation. J Biol Rhythms. 1997;12(1):5-15.

24. Lewy AJ, Sack RL. The role of melatonin and light in the human circadian system. Prog Brain Res. 1996;111:205-16.

25. Sack RL, Lewy AJ, Hughes RJ. Use of melatonin for sleep and circadian rhythm disorders. Ann Med. 1998;30(1):115-21.

26. Skene DJ, Deacon S, Arendt J. Use of melatonin in circadian rhythm disorders and following phase shifts. Acta Neurobiol Exp (Wars). 1996;56(1):359-62.

27. Arendt J, Skene DJ. Melatonin as a chronobiotic. Sleep Med Rev. 2005;9(1): 25-39.

28. Jorgensen KM, Witting MD. Does exogenous melatonin improve day sleep or night alertness in emergency physicians working night shifts? Ann Emerg Med. 1998;31(6):699-704.

29. Sharkey KM, Fogg LF, Eastman CI. Effects of melatonin administration on daytime sleep after simulated night shift work. J Sleep Res. 2001;10(3):181-92.

30. Sharkey KM, Eastman CI. Melatonin phase shifts human circadian rhythms in a placebo-controlled simulated night-work study. Am J Physiol Regul Integr Comp Physiol. 2002;282(2): R454-63.

31. Sack RL, Lewy AJ. Melatonin as a chronobiotic: treatment of circadian desynchrony in night workers and the blind. J Biol Rhythms. 1997;12(6):595-603.

32. Yoon IY, Song BG. Role of morning melatonin administration and attenuation of sunlight exposure in improving adaptation of night-shift workers. Chronobiol Int. 2002;19(5):903-13.

33. James M, Tremea MO, Jones JS, Krohmer JR. Can melatonin improve adaptation to night shift? Am J Emerg Med. 1998;16(4):367-70.

34. Wright SW, Lawrence LM, Wrenn KD, Haynes ML, Welch LW, Schlack HM. Randomized clinical trial of melatonin after night-shift work: efficacy and neuropsychologic effects. Ann Emerg Med. 1998;32(3 Pt 1):334-40.

35. Dawson D, Encel N, Lushington K. Improving adaptation to simulated night shift: timed exposure to bright light versus daytime melatonin administration. Sleep. 1995;18(1):11-21.

36. Gillberg M, Kecklund G, Åkerstedt T. Relations between performance and subjective ratings of sleepiness during a night awake. Sleep. 1994;17(3):236-41.

37. Morin CM. Insomnia: Psychological assessment and management. New York (NY): Guildford Press; 1993.

38. Lisper HO, Kjellberg A. Effects of 24-hour sleep deprivation on rate of decrement in a 10-minute auditory reaction time task. J Exp Psychol. 1972;96(2):287-90.

39. Wilkinson RT, Houghton D. Field test of arousal: a portable reaction timer with data storage. Hum Factors. 1982;24(4):48793.

40. Lowden A, Kecklund G, Axelsson J, Åkerstedt T. Change from an 8-hour shift to a 12-hour shift, attitudes, sleep, sleepiness and performance. Scand J Work Environ Health. 1998;24 suppl 3:69-75.

41. Lamond N, Dawson D, Roach GD. Fatigue assessment in the field: validation of a hand-held electronic psychomotor vigilance task. Aviat Space Environ Med. 2005;76(5):486-9.

42. Lockley SW, Skene DJ, Arendt J. Comparison between subjective and actigraphic measurement of sleep and sleep rhythms. J Sleep Res. 1999;8(3):175-83.

43. Nathan PE, Stuart SP, Dolan SL. Research on psychotherapy efficacy and effectiveness: between Scylla and Charybdis? Psychol Bull. 2000;126(6):964-81.

44. Gibbs M, Hampton S, Morgan L, Arendt J. Adaptation of the 
circadian rhythm of 6-sulphatoxymelatonin to a shift schedule of seven nights followed by seven days in offshore oil installation workers. Neurosci Lett. 2002;325(2):91-4.

45. Terman M, Lewy AJ, Dijk DJ, Boulos Z, Eastman CI, Campbell SS. Light treatment for sleep disorders: consensus report. IV. Sleep phase and duration disturbances. J Biol Rhythms. 1995;10(2):135-47.

46. Wright KP Jr, Gronfier C, Duffy JF, Czeisler CA. Intrinsic period and light intensity determine the phase relationship between melatonin and sleep in humans. J Biol Rhythms.
2005;20(2):168-77.

47. Brzezinski A, Vangel MG, Wurtman RJ, Norrie G, Zhdanova I, Ben-Shushan A, et al. Effects of exogenous melatonin on sleep: a meta-analysis. Sleep Med Rev. 2005;9(1):41-50.

48. Bjorvatn B, Stangenes K, Øyane N, Forberg K, Lowden A, Holsten F, et al. Subjective and objective measures of adaptation and re-adaptation to night work at an oil rig in the North Sea. Sleep. 2006;29(6):821-9.

Received for publication: 26 April 2006 